\title{
F-2-1＼cjkstart磁気浮上遠心血液ポンプにおけるセンサレス流量推定
}

\section{Sensorless flow rate measurement for a maglev centrifugal blood pump}

\author{
土方 亘（束工大） ○阿部 将大（束工大） \\ 正 進士 忠彦（東工大） 高谷 節雄（メドテックハート(株）
}

\begin{abstract}
Shodai ABE, Tokyo Institute of Technology, 4259 Nagatsuta-cho Midori-ku, Yokohama Wataru HIJKATA, Tokyo Institute of Technology, 4259 Nagatsuta-cho Midori-ku, Yokohama Tadahiko SHINSHI, Tokyo Institute of Technology, 4259 Nagatsuta-cho Midori-ku, Yokohama Setsuo TAKATANI, MedTech Heart Inc., 3-24-8, Asakusabashi, Taito-ku, Tokyo
\end{abstract}

\begin{abstract}
A sensorless flow rate measurement has been proposed to control a flow rate in a magnetically levitated centrifugal blood pump without any flow sensor. The proposed algorithm consists of a linear function of the flow rate and the ratio of rotational torque to rotational speed of the impeller. In the range between 0 and 10 $\mathrm{L} / \mathrm{min}$ with a working fluid of water, the error of the estimated flow rate using directly measured torque was less than $0.51 \mathrm{~L} / \mathrm{min}$, which was about a half of the equivalent value using the torque estimated from motor power consumption. Using several working fluids whose viscosity ranged from 0.75 to $3.29 \mathrm{mPa} \cdot \mathrm{s}$, the viscosity was estimated with the error of less than $0.16 \mathrm{mPa} \cdot \mathrm{s}$, from the directly measured torque when the outlet was clamped. Estimated flow rate, compensated by the estimated viscosity, showed the error of less than $0.77 \mathrm{~L} / \mathrm{min}$ in the range of up to $10 \mathrm{~L} / \mathrm{min}$.
\end{abstract}

Key Words: Flow rate estimation, Sensorless measurement, Magnetically levitated centrifugal blood pump

\section{1. 緒 言}

重症心不全患者の治療に, 血液ボンプを用いて血液循環 を代替・補助する, 補助循環が行われている(1). 近年では, 患者の循環状態に合わせた纱液ポンプの流量自動調整が研 究され, 実用化が期待されている.

しかしながら流量計の追加には, 補助循環システムの複 雑化, 高コスト化, センサ故障リスクによる信頼性低下な どの課題がある(2). そこで，既存のハードウェア構成を変 更せず，モータ消費電力等からポンプ流量を推定する研究 が行われているが(3), (4), 同定が困難な複雑な推定式が用い られたり，オンラインでの血液粘度補償ができず，推定精 度が悪かったりするなどの問題がある。

そこで本研究では, 遠心血液ポンプを対象とした, 高精 度化と単純化を両立する流量推定システムの確立を目的と する．具体的には，流量推定に用いるポンプトルクを，従 来のモ一夕消費電力等から推定する方法ではなく, トルク 計にて高精度に測定する. また，血液粘度変化による流量 推定誤差を低減するため, オンライン粘度推定を検討する。

\section{2. 流量 - 粘度推定原理}

本研究では, 図 1 に示す磁気浮上遠心血液ポンプを用い, 流量推定を行う. 電磁石によってインペラを磁気浮上し, 磁気カップリングディスクを介してモータトルクを伝達す る. 本ポンプは体外循環用のため, 血液が接触するポンプ ヘッドを着脱して, 使い捨て可能な構造となっている

ポンプの流量推定原理を，以下に記す．流体抵抗が一定 の条件下では, 遠心ポンプのトルク $\mathrm{T}$, 流量 $\mathrm{Q}$, 回転数 $\omega$ の間に, 以下の関係が成立する.

$$
\begin{aligned}
& \mathrm{T} \propto \omega^{2} \\
& \mathrm{Q} \propto \omega
\end{aligned}
$$

式(1),(2)の関係から，以下の流量推定式を提案する

$$
Q=a^{*}(T / \omega)+K_{1}
$$

ただし $\mathrm{a}$ は定数, $\mathrm{K}_{1}$ は回転数 $\omega$ と作動流体の粘度 $\mu$ に応じて 補正する值である. 本報では, $\omega$ と $\mu$ を変化させた洔の Q と

$\mathrm{T} / \omega の$ 測定結果から, $\mathrm{K}_{1}$ に関する以下の近似式を導出した.

$$
\mathrm{K}_{1}=\left(\mathrm{b}_{1}{ }^{*} \mu+\mathrm{b}_{0}\right) * \omega+\mathrm{c}_{1}{ }^{*} \mu+\mathrm{c}_{0}
$$

$\mathrm{b}_{1}, \mathrm{~b}_{0}, \mathrm{c}_{1}, \mathrm{c}_{0}$ は定数である.

患者の補助循環中に採血等を行わず, 式(4)の血液粘度 $\mu$ の変化をオンラインで補償するために, 粘度推定も行う. 回転数と流体抵抗が一定のとき, 作動流体の粘度変化は, トルク変化に比例する. そこで，回転数を通常の運転条件 に近い 1,500rpm に固定し, アウトレットをクランプして流 体抵抗一定とした状態で, 式(5)により, 粘度を推定する.

$$
\mathrm{T}-\mathrm{T}_{\text {water }}=\mathrm{K}_{2} *\left(\mu-\mu_{\text {water }}\right)
$$

$\mathrm{T}_{\text {water }}$ は, 上記動作条件にて作動流体が水の時のポンプトル ク, $\mathrm{K}_{2}$ は比例定数, $\mu_{\text {water }}$ は水の粘度である. $\mathrm{T}_{\text {water, }}, \mathrm{K}_{2}, \mu_{\text {water }}$ を予め同定しておけば, オンラインでトルク $\mathrm{T}$ を測定する ことで, 粘度 $\mu$ 推定できる。

\section{3. 推定精度評価用の実験装置}

流量・粘度推定の評価システムを, 図 2 に示す. 本シス テムでは，モータと磁気カップリングディスク間にトルク 計を配置した血液ポンプを構成した。モータ消費電力から

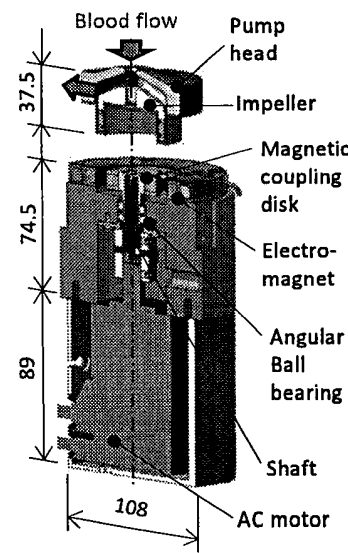

Fig. 1 Configuration of the magnetically-levitated centrifugal blood pump

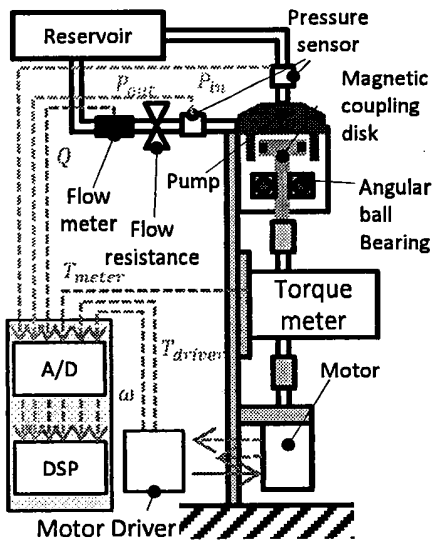

Fig. 2 Schematic view of the measurement system 
推定したトルク $\mathrm{T}_{\text {driver }}$ と, トルク計による直接計測トルク $\mathrm{T}_{\text {meter }}$ のそれぞれを用いて,トルク計測精度が流量推定精度 に及ぼす影響を確認する。

絞り抵抗とリザ一バで循環回路を構成し，恒温槽で作動 流体の温度管理を行う. また, 推定精度の評価用に, 超音 波流量計を接続する. シャフト支持用アンギュラ玉軸受の 損失トルクは, 予め回転数每に計测し, トルク測定值から 減じた上で, 流量・粘度推定を行う。

\section{4. 評価結果}

\section{4・1 トルク計測精度が推定精度に及ぼす影響}

図 3 に, 水を作動流体とした時の, 流量 $\mathrm{Q}$ と $\mathrm{T} / \omega$ の測定 結果を示寸. 式(3)の通り, 回転数一定では 1 次関数の関係 であることを確認した．表 1 に示寸 4 種類の作動流体につ いて同様の測定を行い, 式(3)，(4)の各係数を同定した. そ の結果を, 表 2 に示す.

$37^{\circ} \mathrm{C}$ の水を作動流体とした時の, 式(3)から推定した流量 と流量計出力值の比較を図 4 に示す。なお，この計測では 粘度推定は行わず， $\mu$ は振動式粘度訃で測定した值を推定 式に代入している. 図 4(a)はモータ消費電力から推定した トルク $\mathrm{T}_{\text {driver }}$ を用い, (b)は直接計測したトルク $\mathrm{T}_{\text {meter }}$ を用い た時の推定結果である. 高精度にトルクを測定した図 4(b) の方が推定誤差が約 50\%小さく，0 10L/min の範囲におい て誤差 $0.51 \mathrm{~L} / \mathrm{min}$ 以下の推定精度を実現した。

\section{4-2 自動粘度補償時の流量推定精度}

1,500rpm にてアウトレットをクランプした状態で, 表 1 の 4 種類の作動流体を用いて， $\mu$ - $\mu_{\text {water }}$ と $\mathrm{T}^{-\mathrm{T}_{\text {water }}}$ の関係を 測定した結果を，図 5 に示寸.この結果を直線近似するこ とで, $\mathrm{K}_{2}=1.70 \mathrm{Nm} /(\mathrm{Pa} \mathrm{s})$ と求まった. また，式(5)から推定 した粘度と, 粘度計の出力值を比較した結果を, 図 6 に示 す. 粘度範囲 0.75 3.29mPa s において, 誤差 $0.16 \mathrm{mPa} \mathrm{s}$ 以 下の推定精度が得られた。

$37^{\circ} \mathrm{C}$ の $30 \mathrm{wt} \%, 40 \mathrm{wt} \%, 50 \mathrm{wt} \%$ の各グリセリン水溶液にお いて, 流量推定を行った結果を図 7 に示す. 図 7(a)は粘度 補償せず，40wt\%グリセリン水溶液の粘度を想定して流量 推定した場合で，0 10L/min の範囲において推定誤差は 2.0L/min 以下であった. 図 7(b)は, 図 6 で推定した各粘度 を式(4)に反映した場合であり，推定誤差は $0.77 \mathrm{~L} / \mathrm{min}$ 以下 まで向上することを確認した.

\section{5. 結 言}

遠心血液ポンプ用の流量・粘度推定アルゴリズムを提案 し，推定精度を評価した．提案する流量推定式は単純であ りながら，トルクの高精度測定と粘度補償を行うことで, $0-10 \mathrm{~L} / \mathrm{min}$ の測定範囲にて, 誤差 $0.77 \mathrm{~L} / \mathrm{min}$ 以下の流量推定 精度を実現した. 今後は, 血液ポンプの体内埋込みを想定 し，アウトレットクランプを行わない状態での粘度推定を 検討する予定である。

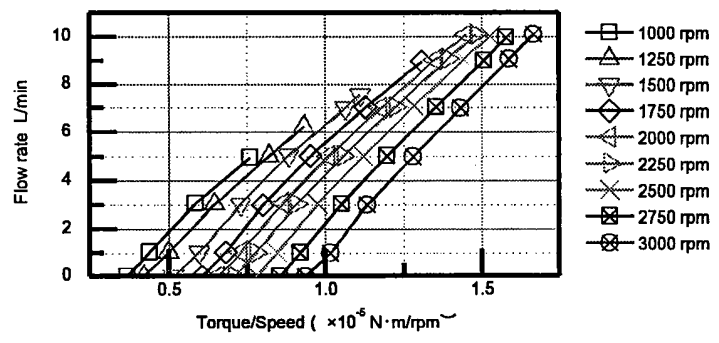

Fig. 3 Relationship between $\mathrm{T} / \omega$ and $\mathrm{Q}$ with water

Table 1 Viscosity of working fluid at $37^{\circ} \mathrm{C}$

\begin{tabular}{c|c}
\multicolumn{2}{c}{ [mPa s] } \\
\hline Water & 0.75 \\
\hline 30wt\% glycerol & 1.61 \\
\hline 40wt\% glycerol & 2.22 \\
\hline 50wt\% glycerol & 3.29 \\
\hline
\end{tabular}

Table 2 Identified parameter

\begin{tabular}{c|c}
\hline $\mathrm{a}[\mathrm{L} \mathrm{rpm} /(\mathrm{Nm} \mathrm{min})]$ & $1.31 \times 10^{6}$ \\
\hline $\mathrm{b}_{0}[\mathrm{~L}]$ & $-4.45 \times 10^{-4}$ \\
\hline $\mathrm{b}_{1}[\mathrm{~L} /(\mathrm{mPa} \mathrm{s})]$ & $-3.30 \times 10^{-3}$ \\
\hline $\mathrm{c}_{0}[\mathrm{~L} / \mathrm{min}]$ & -0.65 \\
\hline $\mathrm{c}_{1}[\mathrm{~L} /(\mathrm{mPa} \mathrm{s} \mathrm{min})]$ & $-9.45 \times 10^{-2}$ \\
\hline
\end{tabular}

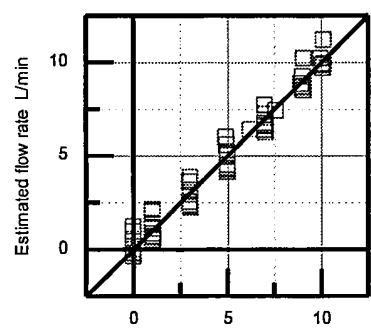

Measured flow rate $L$ min

(a) With torque estimated from motor power

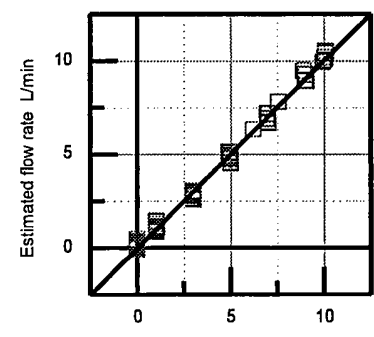

Measured flow rate $\mathrm{Umin}$

(b) With directly measured torque

Fig. 4 Measured flow rate vs. estimated one with water at $37^{\circ} \mathrm{C}$

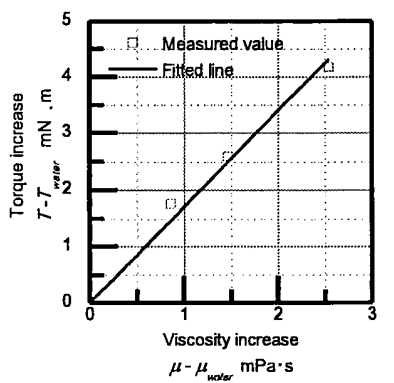

Fig. 5 Relationship between $\mu-\mu_{\text {water }}$ and $\mathrm{T}-\mathrm{T}_{\text {water }}$

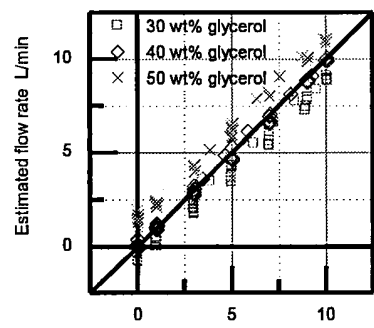

Measured flow rate $\mathrm{L} / \mathrm{min}$

(a) Without viscosity compensation

Fig.7 Estimated flow rate vs. measured one

\section{文献}

(1) H. Hoshi, S. Shinshi and T. Takatani, Third-Generation Blood Pumps With Mechanical Noncontact Bearings, Artificial Organs, 30, 5 (2006), 324-338.

(2) C.D. Bertram, Measurement For Implantable Rotary Blood Pumps, Phisiological Measurement, 26, 4 (2005), 99-117.

(3) T. Tsukiya et al, Use of Motor Current in Flow Rate Measurement For the Magnetically Suspended Centrifugal Blood Pump, Artificial Organs, 21, 5 (1997), 396-401.

(4) M. Granegger et al, Development of a Pump Flow Estimator For Rotary Blood Pumps to Enhance Monitoring of Ventricular Function, Artificial Organs, 36, 8 (2012), 691-699. 